Article

\title{
Temporal Indices of Landscape Change: A Proposal to Measure Variations in the Conservation Status of Vegetation at Fine Resolution
}

\author{
Alberto Luis Cantoral ${ }^{1}{ }^{\mathbb{D}}$, Estrella Alfaro ${ }^{2}{ }^{\mathbb{D}}$, Raquel Alonso-Redondo ${ }^{2} \mathbb{D}$ and \\ Marta Eva García-González 2,*(D) \\ 1 Orocantábrica, Association for the study and conservation of the Natural Heritage of the Cantabrian Range, \\ 16 Carretera Street, Sorriba del Esla, 24815 León, Spain; albertoluis.cantoral@orocantabrica.org \\ 2 Botany Area, Department of Biodiversity and Environmental Management, Faculty of Biological and \\ Environmental Sciences, University of León, Campus de Vegazana, E-24071 León, Spain; \\ estrella.alfaro@unileon.es (E.A.); raquel.alonso@unileon.es (R.A.-R.) \\ * Correspondence: megarg@unileon.es
}

Received: 17 September 2019; Accepted: 17 October 2019; Published: 23 October 2019

check for updates

\begin{abstract}
The goal of this study was to propose scientific and objective indices capable of measuring the changes that occur in the conservation status of the vegetation of a particular area over a period of time. To this end, phytosociologically-based vegetation cartography at a detailed scale was used, carried out at two different times, and the distance from the climax stage of the territory was calculated for each time. Three temporal indices of landscape change are proposed: Conservation Status Variation Index (ConSVI), Conservation Status Variation Velocity Index (ConSVVe) and Change Ratio (ChanRat). These enable the intensity, velocity, and percentage of change to be measured, and to determine whether this change is progressive or regressive-in other words, whether it is approaching or receding from the climax. To test the proposal, it was applied to a territory in Northwest Spain. The proposed indices are universally applicable to any territory and are the first of their kind to operate at a detailed scale with a phytosociological basis. They also enable an objective measurement to be made of the landscape change that has occurred, meaning that they have immense practical utility in studies of managing and planning territorial resources.
\end{abstract}

Keywords: landscape changes; potential vegetation; temporal change indexes; valuation; vegetation conservation; vegetation mapping

\section{Introduction}

Vegetation changes as a result of ecological processes that act at different temporal and spatial scales [1]. It is necessary to understand vegetation changes in order to manage natural habitats. Toward this end, the classification of vegetation aims to summarize the variation of vegetation using a limited number of abstract entities [1]. Natural plant communities must therefore be differentiated from plantations, crops, and other non-natural formations. Such formations have benefited in recent years from the development of the human economy, with an attendant reduction in native forests. The natural resources management applied over the course of recent decades has not managed to stop the disappearance of natural vegetation. However, rural areas affected by depopulation and the reduction of livestock and agricultural impacts could improve the state of conservation of native forests.

How to measure the conservation status of vegetation is a question that has been approached in various scenarios [2], some of them based on the study of phytosociological communities at the landscape level [3-5] and others requiring a more complete and detailed knowledge of plant composition. In accordance with other research [6], ecological studies need to be contextualized within 
the frame of a vegetation typology, since the vegetation type being assessed may considerably affect the results of the studies.

The present study proposes to measure the variations in the conservation status of a territory's vegetation based on a phytosociological typology. Phytosociology is a branch of vegetation science that studies, among other concepts, current plant communities at the spatial size of vegetation patches [7]. Current phytosociology takes a statistical approach that aims to characterize vegetation types by the combined information from many different plots. Symphytosociology is the division of phytosociology that studies plant communities in their different states and how they replace each other according to their state of maturity in a specific homogeneous area [8,9]. The typological unit in symphytosociology is the sigmetum or vegetation series. Vegetation series includes the vegetation type representative of the series head and the serial communities that precede or replace it [10-12]. Thus, conservation status is viewed from a dynamic-serial perspective, as a measure of the distance to the hypothetical situation in which the entire territory is occupied by the series head or climax plant communities concerned.

The landscape level is needed to reflect vegetation health status in real time. The scale of the work and the typology of the markings that are used to divide up the landscape are conditioned by this level. From this perspective, the landscape can be regarded as a spatial configuration of markings of relevant dimensions for the phenomenon in question [13]. When the scale and perception of the analysis require the classification of the landscape mosaic based on vegetation markings, the use of excessively simplistic systems may lead to a loss of information, undermining the description of the place being studied. An example of this would be the decision to unify different scrubland communities within a single type when classifying the Orocantabrian landscape. Even communities that are close to each other in physiognomic and syntaxonomic terms may comprise totally distinct ecosystems reflecting different local climate conditions, playing a distinct serial role and harboring a different ecological complex [14]. The level of detail the researcher decides to use, depending on the goals set for the study, should account for the loss of information caused when choosing the types of landscape. When asking oneself what to differentiate and what to aggregate, one needs to be aware of the loss entailed by one's choice; there will be a need to base the decision on knowledge of the landscape's components-something that nearly always requires an appropriate floristic and vegetational foundation, without which the results may be erroneous.

From the 1970s to the present day, many efforts have been made to link satellite imagery and vegetation cover [15]. Specifically, near the study area, attempts have been made to study the recent dynamics of the landscape through aerial photographs [16]. Based on the previous attempts to detect changes in the vegetation cover, various indices have been proposed, most of them based on remote sensing data for land-cover change analysis, using measurements derived from infrared radiation and Landsat images $[15,17-20]$. Some of these indices are widely used, such as the normalized difference vegetation index (NDVI) [21] and the enhanced vegetation index (EVI) [22]. These approaches are based on vegetation changes emerging from the study of satellite and orthophotographic images, which calculate an index or ratio derived from a series of numerical parameters. The potential of these vegetation indices has been validated by studies that analyze crop yields [23]. In general, such indices are applied to large territories and on not a fine scale. However, few studies propose indices that address changes in vegetation based on its state of maturity. For example, recently published research assesses change in vegetation in terms of the growth or shrinkage of plant cover, but does not take into account the naturalness of the change $[24,25]$. Structural changes in vegetation have also been addressed in recent works that analyzed this parameter on the basis of its homogeneity [25] or some very broad vegetation classes [26].

In order to be able to determine vegetation change, this study proposes indices that enable the conservation status of a territory to be calculated at a certain period of time and to compare it with an earlier period. Toward this end, the authors rely on symphytosociological concepts, according to which the optimal conservation status of a territory arises when it arrives at climax in all of its points [27]. The proposed indices enable researchers to ascertain and quantify how this conservation status of the 
territory varies in its entirety over time. It should thus be possible to determine whether the change in vegetation of a specific area is progressive, regressive, or neutral. The proposed approximation could be complementary to other indices, providing a type of information that may prove crucial in decision-making. This proposal could be very useful for determining the correct measures required in a territory and for interpreting the results obtained from the analysis of satellite images.

\section{Materials and Methods}

First, having selected the working area on which the various vegetation indices are going to be applied, the level of detail and required scale were established. Vegetation patches were defined as physiognomically homogeneous units with a shared tonality and texture that could be differentiated from the surroundings with the help of GIS (Geographic Information Systems). In order to be able to carry out a comparison at the landscape level, we used orthophotographs and georeferenced aerial photographs from different periods of time.

All operations involving the use of GIS were performed with ArcGIS ${ }^{\circledR}$ software [28].

An important part of planning the work consisted of establishing the units or types of vegetation common to both moments, such that they enable the plant classification of the landscape and enable analysis of the changes that have taken place. These types of vegetation correspond to the grouping of communities that appear together on a detailed map, and were established as a new unit of work (Supplementary Materials, Annex 1).

Having established the types of vegetation, in order to determine the changes in the plant cover, the Potentiality Distance Index (PDI) put forward by Penas et al. [4] was used. This index helped us to interpret the state of conservation of the territory at the landscape scale, understanding it as a measure of the distance to the hypothetical situation in which the entire territory is occupied by the corresponding climax communities. According to the latter, the PDI for a given territory is calculated as the sum of the Potentiality Distance values for each type of vegetation $\left(D I_{i}\right)$ multiplied by the relative area occupied by that type of vegetation $\left(\Omega_{\mathrm{i}}\right)$ compared to the total surface area in question $\left(\Omega_{\mathrm{T}}\right)$ :

$$
P D I=\sum_{i=1}^{n}\left(D I_{i} x \frac{\Omega_{i}}{\Omega_{T}}\right)
$$

where $D I=1-[(3 \mathrm{P}-N I) / 3 n]$

and

P: ordinal position that the vegetation type occupies in its respective vegetation series relative to the head of series;

$\mathrm{n}$ : defined number of permissible stages resulting from the succession process;

NI: Naturalness Index, proposed by Penas et al. [4] which assigns a weighting to the anthropic influence in the area where the vegetation type in question is located [29].

The PDI ranges of variation proposed by [4], as set out in Table 1, were reviewed and modified by the authors of the present study.

Table 1. Relationship between the values of the Potentiality Distance Index (PDI), the distance to the head of series and the conservation status (after Penas et al. [4] with corrections).

\begin{tabular}{ccc}
\hline $\boldsymbol{P D I}$ & Distance to the Head of Series & Conservation Status \\
\hline$\leq 0.25$ & Very distant & Poor \\
$0.25-0.50$ & Distant & Moderate \\
$0.50-0.75$ & Moderately distant & Good \\
$>0.75$ & Not very distant/Not distant & Very good \\
\hline
\end{tabular}

A temporal dimension was incorporated into the PDI by studying the same territory at two different moments in time. Three new indices are proposed, which will jointly be referred to as 
temporal indices of landscape change and which enable an assessment to be made of the change that has taken place in the landscape over this passage of time. They are the Conservation Status Variation Index (ConSVI), Conservation Status Variation Velocity (ConSVVe), and Change Ratio (ChanRat).

\subsection{New Proposal: Formulation}

\subsubsection{Conservation Status Variation Index (ConSVI)}

$$
\text { ConSVI }=\text { PDIf }- \text { PDIi, }
$$

where

ConSVI is the Conservation Status Variation Index;

$P D I_{\mathrm{f}}$ is the Final Potentiality Distance Index;

$P D I_{i}$ is the Initial Potentiality Distance Index.

This index is the difference in the Potentiality Distance Index (PDI) value of the territory at the end of the passage of time in question $\left(P D I_{f}\right)$ and the territory's $P D I$ value at the outset of this passage of time $\left(P D I_{i}\right)$.

In order to apply this index, a vegetation map is generated for each point in time of the comparison.

Positive ConSVI scores indicate the recovery or dominance of a progressive direction in the plant succession-in other words, that there has been a narrowing of the distance to the respective heads of series in the dynamic processes. Therefore, an increase in the conservation status of the territory at the landscape scale is deemed to have occurred. Negative ConSVI scores on the other hand reveal a widening distance or regressive direction of the succession relative to the respective climax communities; therefore, a reduction in the conservation status of the territory is deemed to have taken place at the landscape scale. The absolute value of the ConSVI indicates the intensity of the progressive or regressive forces over the passage of time in question. This index can vary between -1 and +1 , and seven categories were established as set out in Table 2.

Table 2. Relationship between the Conservation Status Variation Index (ConSVI) scores and the variation in the territory's conservation status.

\begin{tabular}{cc}
\hline ConSVI Scores & Variation in Conservation Status \\
\hline-1 to -0.5$)$ & Highly negative \\
-0.5 to -0.25$)$ & Negative \\
-0.25 to 0 & Moderately negative \\
0 & Neutral \\
0 to 0.25 & Moderately positive \\
0.25 to 0.5 & Positive \\
0.5 to 1 & Highly positive \\
\hline
\end{tabular}

2.1.2. Conservation Status Variation Velocity Index (ConSVVe)

$$
\text { ConSVVe }=\frac{C o n S V I}{N}
$$

where

ConSVVe is the Conservation Status Variation Velocity;

ConSVI is the Conservation Status Variation Index;

$N$ is the number of decades (number of years of the time interval/10).

This is deemed to be the variation in the conservation status of a territory over a unit of time. ConSVVe enables the conservation status variation (ConSVI) to be calculated in relative terms depending on the duration of the temporal series, and for the variations in the conservation status that have occurred in different zones to be compared relative to the potentiality distance at the landscape level 
over a certain period of time. The authors established a decade as the minimum temporal unit for dynamic-serial studies. It was considered that whereas regressive anthropic processes may take place over short periods of time (plantations, crops, clearance operations, opening mines, urbanization, etc.), dynamic-serial natural processes occur much more slowly, and their detectability was therefore estimated at ten years. ConSVVe retains the positive/negative sign of its respective ConSVI, entailing that a negative velocity indicates regression in the conservation status of a territory, and a positive velocity indicates an improvement.

This index ranges between -1 and +1 . Higher positive values represent a faster recovery velocity towards the climactic stage. When the index has negative values, the higher its absolute values the greater the velocity of degradation will be-in other words the distance from the climax (Table 3).

Table 3. Relationship between the Conservation Status Variation Velocity Index (ConSVVe) scores and the variation in the territory's conservation status over a unit of time.

\begin{tabular}{cc}
\hline ConSVVe Scores & Variation in Conservation Status Over a Unit of Time \\
\hline-1 to -0.5$)$ & Rapid degradation \\
-0.5 to -0.25$)$ & Moderate degradation \\
-0.25 to 0 & Slow degradation \\
0 & Neutral \\
0 to 0.25 & Slow recovery \\
0.25 to 0.5 & Moderate recovery \\
0.5 to 1 & Rapid recovery \\
\hline
\end{tabular}

\subsubsection{Change Ratio (ChanRat)}

$$
\text { ChanRat }=\frac{\text { ConSVVe }}{\text { PDIi }} \times 100
$$

This index is derived by calculating the variation observed in the conservation status over the time period being studied relative to the initial conservation status. In other words, it derives from the values of ConSVVe and $P D I_{i}$. It represents the ratio of the change observed per decade elapsed to the initial conservation status, and is expressed as a percentage. Thus, in two scenarios where the variation velocity is the same, the landscape with the lower initial conservation status (i.e., smaller $P D I_{i}$ value) will have the higher change ratio. The percentage of change in the landscape will be greater if the initial situation reflects more degraded successional stages. This ratio emphasizes the degree of recovery or alteration based on landscapes with a predominance of initial successional stages that are far removed from the hypothetical climactic situation. Negative ChanRat scores indicate regressive alterations, whereas positive scores indicate recovery or progressive changes towards the climax.

These three indices enable researchers to assess the progressive or regressive changes occurring in a territory in an objective manner and to quantify them in relation to the conservation status (increase, decrease, maintenance) based on knowledge of the types of vegetation present in the territory and their dynamic-serial significance in the landscape.

\subsubsection{An Applied Example of Temporal Change Indices}

In order to validate these indices, a territory located in the Cantabrian Mountains (León, Spain) was selected. It is made up of the sub-basin of the Dueñas river and has a surface area of $55.85 \mathrm{~km}^{2}$ (Figure 1). The district exhibits the typical topography of a mid-mountain landscape, comprising materials from the Paleozoic age, mainly highly fissured limestones and sandstones, pertaining to the Central Carboniferous Basin. The valley, which is approximately $11 \mathrm{~km}$ in length, is bounded by ridges and peaks with an altitude of around $2000 \mathrm{~m}$. The average altitude is $1400 \mathrm{~m}$, with a pronounced average slope of $21^{\circ}$. From a biogeographical perspective it belongs to the Orocantabrian subprovince (European Atlantic Province, Atlantic-Central European Subregion, Eurosiberian Region). The predominant bioclimatic threshold is the supratemperate hyperhumid, where woods of beech and 
oak (Quercus petraea (Mattuschka) Liebl., Q. pyrenaica Willd.) flourish, followed by the orotemperate hyperhumid, which approximately occupies altitudes superior to $1600 \mathrm{~m}$ and where creeping junipers predominate. There are four small hamlets in the district, with a combined population of 118 inhabitants. The traditional manner of farming the mountain has molded a pastoral landscape that is now undergoing transformation owing to new uses. The uniform environmental and socioeconomic conditions enable the pertinent anthropic variables to be analyzed within the framework of the changes that have occurred in the territory [14].
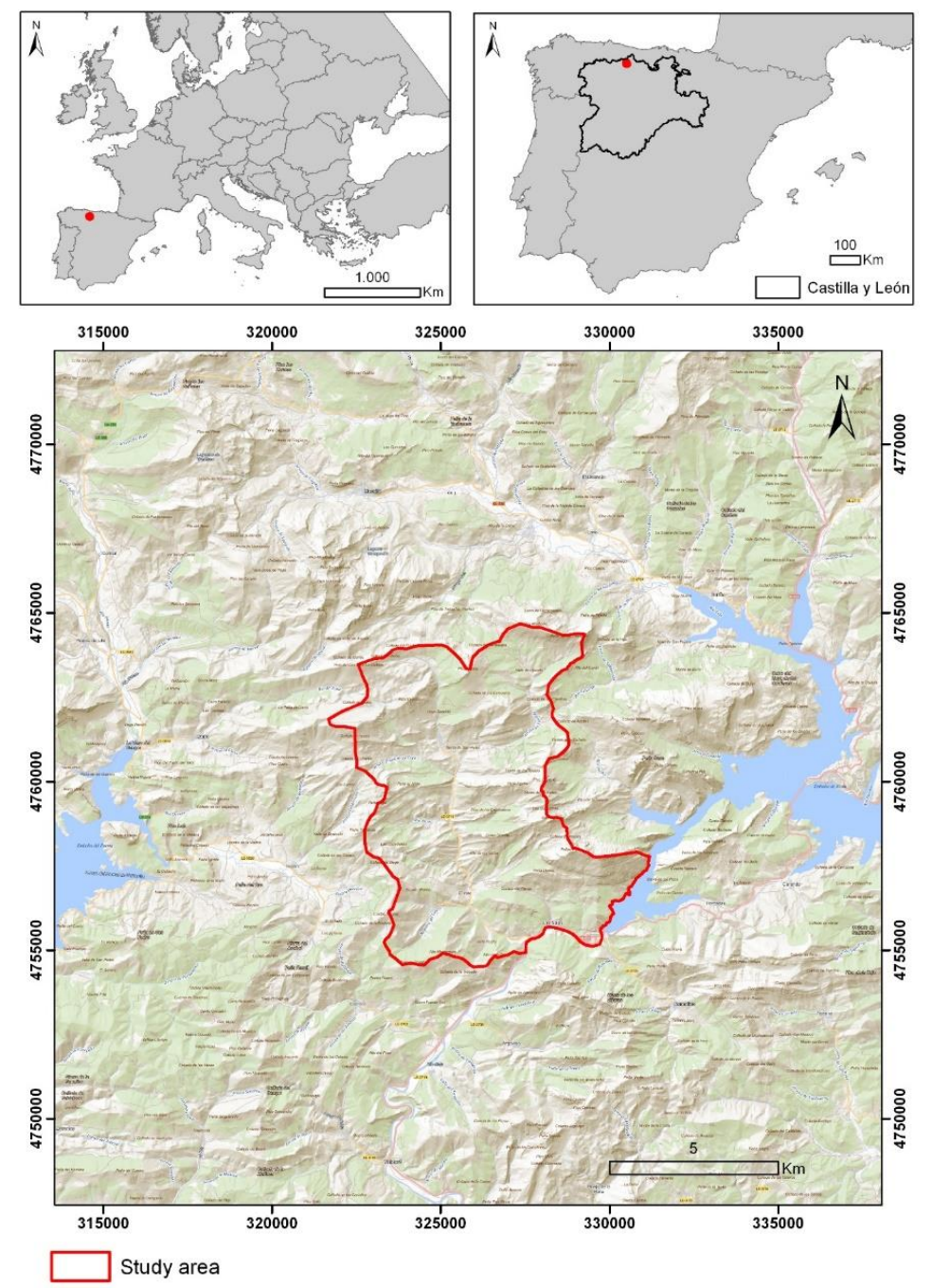

Figure 1. Location of the study area (León, Spain).

In order to ascertain the current vegetation, the authors established the UTM (Universal Transverse Mercator) grid of $1 \mathrm{~km}^{2}$ as the working scale to delimit the patches, which led to the issuing of information layers at a fixed on-screen scale of 1:3000. Once the current vegetation was established and the types of vegetation ascertained, cartography was carried out at a scale of 1:65,000 and at two different times, 1957 and 2008. These years were selected because they corresponded to the oldest and most modern years of flight available, so this time period is a proof of concept. The DI for the vegetation types was calculated, as was the $P D I_{i}$ for the landscape in 1957 and the $P D I_{f}$ for the landscape in 2008. Using these figures, the authors applied the indices set out above to ascertain the changes in the territory's conservation status occurring over the course of the 51 years in question. In order to detect natural dynamic-serial processes (slower in time than those related to human action), the oldest series of aerial photographs available was selected for this study. 
The fundamental tools used to carry out the cartography of the vegetation were orthophotography (for 2008) and georeferenced aerial photography (for 1957) (Figure 2). The orthophotographs derive from the summer photogrammetric flight carried out within the framework of the National Aerial Orthophotographic Plan (PNOA), in .ecw (enhanced compression wavelet) format. Each orthophotograph corresponds to a raster of 14,240 columns and 10,040 rows, with a cell size of $0.25 \times 0.25$ and a pixel depth of 8 Bits, which encompasses approximately $3.28 \times 2.51 \mathrm{~km}^{2}$. The aerial photographs used to analyze the earlier landscape derive from digitalized stills from a flight in 1957, not ortho-corrected, saved in Geotiff format, with $6780 \times 6071$ pixels, 600 ppp, and 8 Bits of depth, held in the cartographic archives of the Duero Hydrographic Confederation [30].
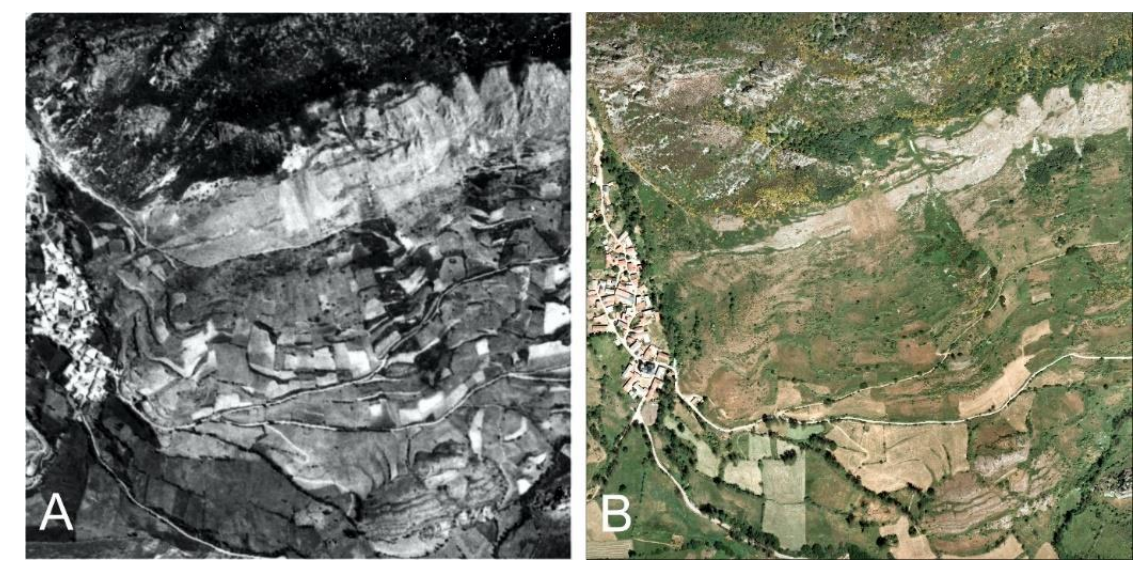

Figure 2. Example of photographs used (images of cell $1 \times 1 \mathrm{~km}^{2} 30 \mathrm{TUN} 2561$ ): (A) Georeferenced black and white aerial photography 1957. (B) Real color orthophotography 2008.

The 1957 stills in Geotiff format exhibited serious errors of calibration, some as great as $\pm 300 \mathrm{~m}$. To remedy this, the authors carried out a new prior referencing for each still that reduced the error to a maximum of $\pm 100 \mathrm{~m}$.

Each type of vegetation is defined by a physiognomic structure, a dynamic-serial context and a single naturalness index (NI), combined with height, bioclimatic, and geological data. This provided the foundation for applying the new indices using two maps of the area's vegetation, showing the landscape in 1957 and 2008 (Figure 3).

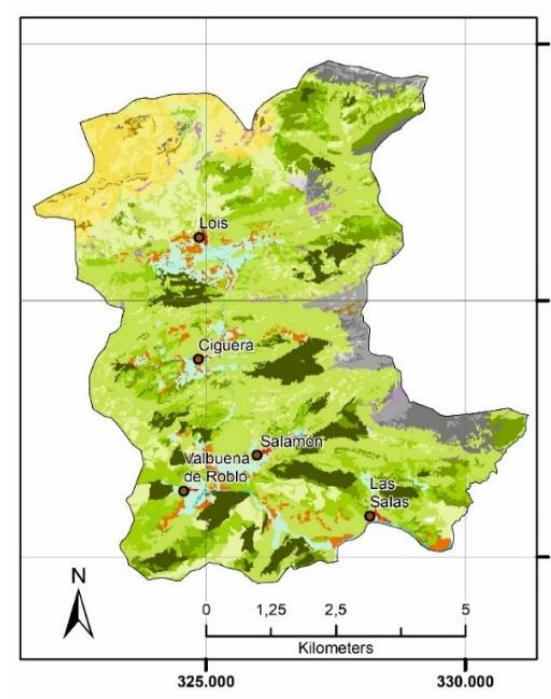

Vegetation map in 1957

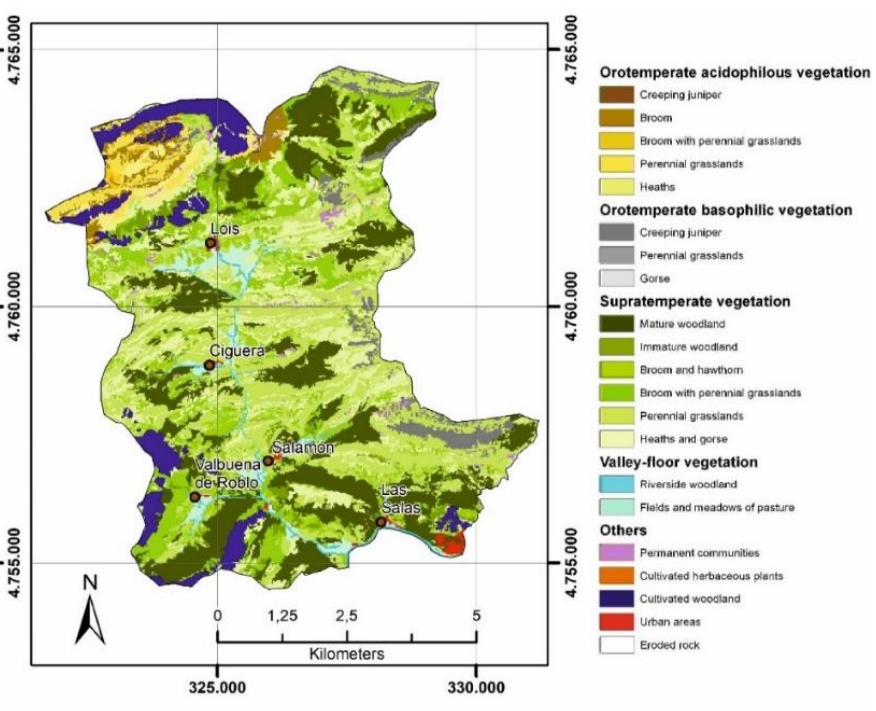

Vegetation map in 2008

Figure 3. Cartography of the vegetation in the sample territory at two points in time: 1957 and 2008. 
A final map of the variation in the conservation status of the vegetation was made. To do this, a vectorial information layer (corresponding to a continuous surface formed by the union of different polygons defined by a type of vegetation in 1957 and 2008) was converted to raster format. The pixel size was $20 \mathrm{~m}^{2}$ and contained the $D I$ value of each type of vegetation. The difference between the final and initial states at pixel level was calculated. The subtraction of the final and initial raster layers allowed another layer to be obtained that reflects the evolution of the vegetation. The final map was reclassified into three classes: no change, progressive direction (advancement to climax), or regressive direction.

\section{Results}

\subsection{Calculation of DI, PDIi, and PDIf}

Table 4 shows the values calculated for the DIs of each of the territory's vegetation types, the surface area covered by these in both 1957 and 2008, the $P D I_{i}$ value for 1957, and the $P D I_{f}$ for 2008 . Twenty-five vegetation types were identified in the territory.

Table 4. Types of mapped vegetation and the calculation of the PDI at the landscape scale in $1957\left(P D I_{i}\right)$ and $2008\left(P D I_{f}\right)$. P: position of the vegetation type in the dynamic-serial process; n: number of possible serial stages; NI: naturalness index; $D I$ : distance to the potentiality; $\Omega_{\mathrm{i}}$ : surface area covered by each vegetation type. $\Omega_{\mathrm{T}}$ : total surface area.

\begin{tabular}{|c|c|c|c|c|c|c|c|c|}
\hline \multirow[b]{2}{*}{ Types of Vegetation } & \multirow[b]{2}{*}{$\mathbf{P}$} & \multirow[b]{2}{*}{$\mathbf{n}$} & \multirow[b]{2}{*}{$N I$} & \multirow[b]{2}{*}{$D I$} & \multicolumn{2}{|c|}{1957} & \multicolumn{2}{|c|}{2008} \\
\hline & & & & & $\Omega_{\mathrm{i}}(\mathrm{ha})$ & $\begin{array}{c}D I \times \\
\left(\Omega_{\mathrm{i}} / \Omega_{\mathrm{T}}\right)\end{array}$ & $\Omega_{\mathrm{i}}$ (ha) & $\begin{array}{c}D I \times \\
\left(\Omega_{\mathrm{i}} / \Omega_{\mathrm{T}}\right)\end{array}$ \\
\hline \multicolumn{9}{|l|}{ Azonal Communities } \\
\hline Permanent orotemperate communities & 1 & 1 & 3 & 1 & 12.04 & 0.0022 & 10.2 & 0.0018 \\
\hline Permanent supratemperate communities & 1 & 1 & 3 & 1 & 32.48 & 0.0058 & 42.88 & 0.0077 \\
\hline Basophilic creeping juniper & 1 & 1 & 3 & 1 & 85.6 & 0.0153 & 83.32 & 0.0150 \\
\hline \multicolumn{9}{|l|}{ Orotemperate acidophilous vegetation } \\
\hline Creeping juniper & 1 & 4 & 3 & 1 & 2.16 & 0.0004 & 4.36 & 0.0008 \\
\hline Broom & 2 & 4 & 3 & 0.75 & 24.72 & 0.0033 & 120.8 & 0.0163 \\
\hline Broom with Orocantabrian oak & 1 & 1 & 3 & 1 & 0 & 0 & 3.2 & 0.0006 \\
\hline Broom with perennial grasslands & 2 & 4 & 1 & 0.58 & 1.56 & 0.0002 & 11.92 & 0.0012 \\
\hline Perennial grasslands & 3 & 4 & 3 & 0.5 & 211.48 & 0.0190 & 114.88 & 0.0103 \\
\hline Heaths & 4 & 4 & 2 & 0.17 & 266.64 & 0.0080 & 99.28 & 0.0030 \\
\hline Cultivated woodland & 8 & 8 & 1 & 0.04 & 0 & 0 & 153.68 & 0.0012 \\
\hline \multicolumn{9}{|l|}{ Orotemperate basophilic vegetation } \\
\hline Creeping juniper & 1 & 3 & 3 & 1 & 96.52 & 0.0174 & 95.12 & 0.0171 \\
\hline Perennial grasslands & 2 & 3 & 3 & 0.67 & 153.84 & 0.0184 & 134.44 & 0.0161 \\
\hline Gorse & 3 & 3 & 2 & 0.22 & 16 & 0.0006 & 37.12 & 0.0015 \\
\hline \multicolumn{9}{|l|}{ Supratemperate vegetation } \\
\hline Mature woodland & 1 & 7 & 3 & 1 & 436.12 & 0.0784 & 1181.88 & 0.2125 \\
\hline Immature woodland & 1 & 7 & 1 & 0.90 & 375.64 & 0.0611 & 152.28 & 0.0248 \\
\hline Broom and hawthorn & 3 & 7 & 2 & 0.67 & 293.92 & 0.0352 & 604.72 & 0.0725 \\
\hline Broom with perennial grasslands & 3 & 7 & 1 & 0.62 & 341.2 & 0.0380 & 164.6 & 0.0183 \\
\hline Perennial grasslands & 4 & 7 & 2 & 0.52 & 2186.36 & 0.2059 & 1376.36 & 0.1296 \\
\hline Heaths and gorse & 5 & 7 & 2 & 0.38 & 597.48 & 0.0409 & 734.64 & 0.0503 \\
\hline Eroded rock & 7 & 7 & 1 & 0.05 & 5.36 & 0 & 1.6 & 0 \\
\hline Urban areas & 8 & 8 & 1 & 0.04 & 10.76 & 0.0001 & 25.6 & 0.0002 \\
\hline Cultivated woodland & 8 & 8 & 1 & 0.04 & 0 & 0 & 200.8 & 0.0015 \\
\hline Cultivated herbaceous plants & 8 & 8 & 1 & 0.04 & 244.24 & 0.0018 & 0.44 & 0 \\
\hline \multicolumn{9}{|l|}{ Valley-floor vegetation } \\
\hline Riverside woodland & 1 & 5 & 1 & 0.87 & 15.16 & 0.0024 & 61.12 & 0.0095 \\
\hline Fields and meadows of pasture & 4 & 5 & 2 & 0.33 & 151.2 & 0.0091 & 146.52 & 0.0088 \\
\hline Bodies of water & - & - & - & - & 2.16 & - & 0.92 & - \\
\hline & & & & & $\Omega_{\mathrm{T}}=5562.68$ & $P D I_{i}=0.5636$ & $\Omega_{\mathrm{T}}=5562.68$ & $P D I_{f}=0.6205$ \\
\hline
\end{tabular}

The $P D I_{i}$ value was 0.564 . This value suggests a landscape moderately removed from the climax communities and a good conservation status. The $P D I_{f}$ value was 0.621 . This value also suggests a landscape moderately removed from the climax communities and therefore that the overall conservation status of the territory is good. Although both values fall within the variation range of the 
index, the higher value obtained for 2008 suggests a better state of plant conservation in the territory compared to 1957.

\subsection{Calculation of the Temporal Indices of Landscape Change: ConSVI, ConSVVe, and ChanRat}

The intensity and velocity of the changes at the landscape level over the period of time in question are shown in the following results (Table 5).

Table 5. Scores for the indices calculated for the study area: initial indices $\left(P D I_{i}\right.$ and $\left.P D I_{f}\right)$ and temporal change indices (ConSVI, ConSVVe, and ChanRat).

\begin{tabular}{ccc}
\hline Indices & Abbreviation & Score \\
\hline Initial indices & & \\
Potentiality Distance Index, 1957 & $P D I_{i}$ & 0.5636 \\
Potentiality Distance Index, 2008 & $P D I_{f}$ & 0.6205 \\
\hline Temporal change indices & & \\
Conservation Status Variation Index & ConSVI & 0.0569 \\
Conservation Status Variation Velocity & ConSVVe & 0.0112 \\
Conservation Status Change Ratio (\%) & ChanRat & 1.9813 \\
\hline
\end{tabular}

The conservation status variation index (ConSVI) obtained a score of 0.057 , which falls within the "moderately positive" range (Table 2). This indicates a recovery (albeit small) or a predominance of the progressive direction in the plant succession. Put another way, over the interval concerned, the distance to the respective heads of series in the dynamic processes narrowed. The authors therefore conclude that there has been a small enhancement in the degree of conservation of the territory at the landscape level between 1957 and 2008.

The score for the conservation status variation velocity (ConSVVe) was 0.011 , which falls within the range of "slow recovery" over 10 years (Table 3).

The rate of change (ChanRat) obtained was close to $2 \%$; this reflects the proportion represented by the observed change per decade relative to the initial conservation status. The rate of change was positive, albeit small, which indicates a change in a progressive direction from a scenario that was not very distant from the climax. The rate of change will enable future comparisons to be made with other territories.

The results of the three indices are clearly linked to each other. The positive values of the three indices indicate that the territory is recovering towards climax: ConSVI shows a moderate intensity of this progressive evolution, ConSVVe indicates that this recovery is slow, and ChanRat points to a small change as the territory was not much altered in its initial state. Although the first index can be applied alone, the others detail and complete the information on the changes that have occurred in the vegetation. All of them are very useful and complement each other.

\subsection{Changes in the Structure of the Vegetation in the Sample Territory}

The results of analyzing the cartography of the vegetation in the sample territory at the two points in time are shown in Figure 3. Annex 1 shows the correspondence between types of vegetation and phytosociological communities. In 1957, the landscape was dominated by the following types of vegetation: supratemperate perennial grasslands $(39.30 \%)$, supratemperate chamaephytic scrubland (heaths and gorse) (10.74\%), mature woodlands $(7.84 \%)$, immature woodlands $(6.75 \%)$, and a mosaic of supratemperate nanophanerophytic scrubland and perennial grasslands (broom and dandelion pastures) (6.13\%). Grouping these together in large physiognomic units (grassland/scrubland/woodland), the overall pattern has the proportions 2.7/1.5/1. In 2008, the landscape was dominated by three types of vegetation: supratemperate perennial grassland $(24.74 \%)$, mature woodland $(21.25 \%)$, supratemperate chamaephytic scrubland $(13.21 \%)$, supratemperate nanophanerophytic scrubland (broom and hawthorn) (10.87\%), and orotemperate basophilous creeping 
juniper (7.71\%). Grouping these together in large physiognomic units (grassland/scrubland/woodland), the overall pattern is characterized by the proportions $1 / 1.1 / 1$. The percentages were calculated by measuring the surface areas occupied by each type of vegetation in the vectorial layer generated by the ArcGIS software.

A final map of variation in the conservation status of vegetation in the studied time period is shown in Figure 4. The land cover change data are shown in Table 6. In the entire territory studied, the percentage of vegetation cover in which no changes occurred was $39.62 \% ; 35.85 \%$ of the territory advanced towards a climax state (progressive direction), while $24.53 \%$ moved away from the climax state (regressive direction).

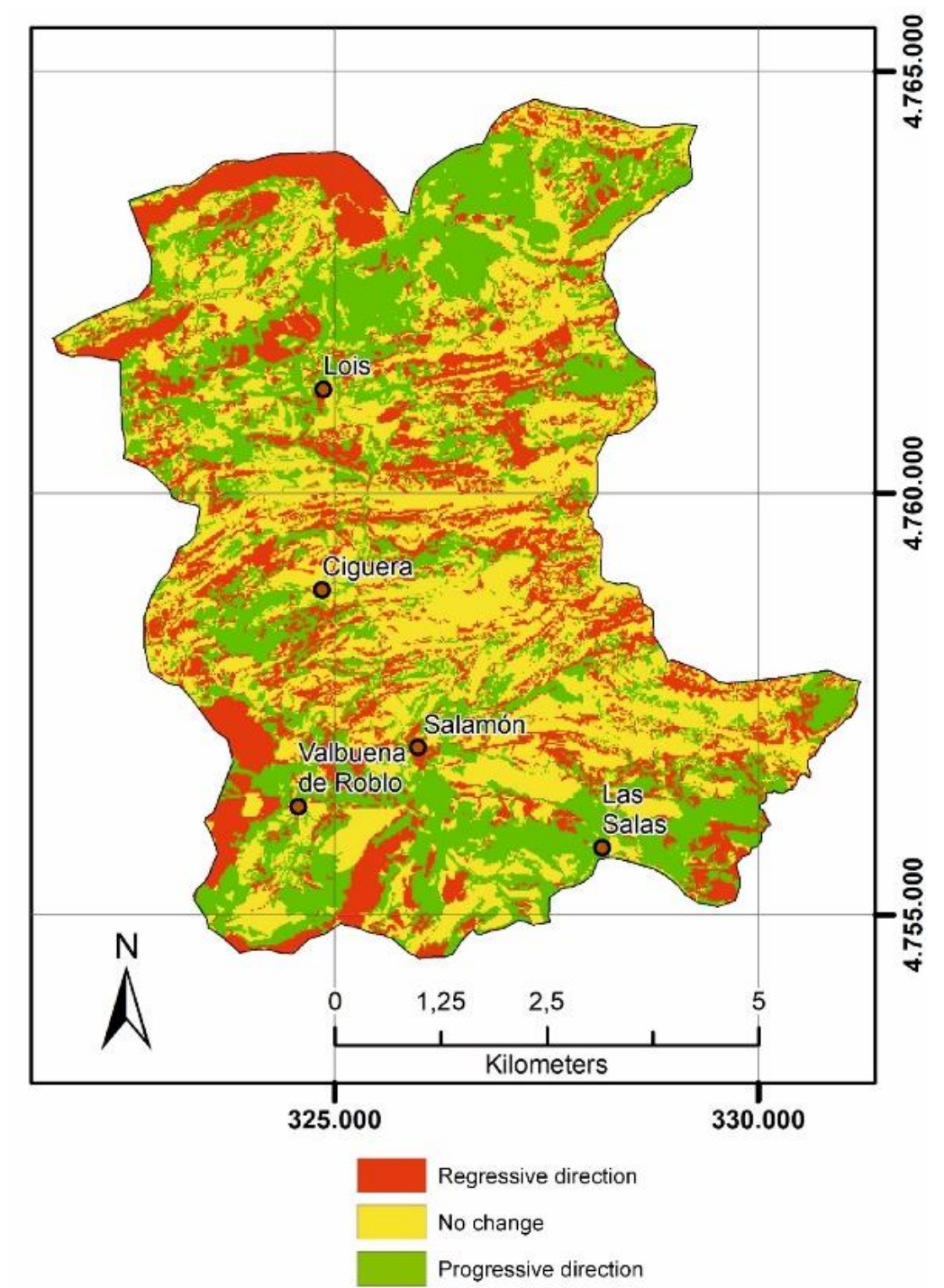

Figure 4. Map of variation in the conservation status of vegetation over the 50 years of study. 
Table 6. Land cover change: Variation in surface area (ha) of each type of vegetation, calculated by subtracting the cover in 2008 from the area occupied by this type of vegetation in 1957. Rate of change: percentage representing the change in relation to the initial coverage. Percentage data of stability, regression, and progression of the different types of vegetation.

\begin{tabular}{|c|c|c|c|c|c|}
\hline Types of Vegetation & Land Cover Change (ha) & Rate of Change (\%) & Stability (\%) & Regression (\%) & Progression (\%) \\
\hline \multicolumn{6}{|l|}{ Azonal communities } \\
\hline Permanent orotemperate communities & -1.84 & -15.28 & 72.42 & 27.57 & 0 \\
\hline Permanent supratemperate communities & 10.4 & 32.02 & 88.92 & 10.22 & 0 \\
\hline Basophilic creeping juniper & -2.28 & -2.66 & 55.33 & 42.80 & 0 \\
\hline \multicolumn{6}{|l|}{ Orotemperate acidophilous vegetation } \\
\hline Creeping juniper & 2.2 & 0 & 3.70 & 96.3 & 0 \\
\hline Broom & 96.08 & 0 & 53.88 & 39.48 & 6.63 \\
\hline Broom with Orocantabrian oak & 3.2 & - & - & - & - \\
\hline Broom with perennial grasslands & 10.36 & 664.10 & 0 & 30.77 & 69.23 \\
\hline Perennial grasslands & -96.6 & -45.68 & 38.30 & 32.70 & 28.99 \\
\hline Heaths & -167.4 & -62.77 & 25.31 & 41.14 & 33.54 \\
\hline Cultivated woodland & 153.68 & - & - & - & - \\
\hline \multicolumn{6}{|l|}{ Orotemperate basophilic vegetation } \\
\hline Creeping juniper & -1.4 & -1.45 & 56.61 & 43.30 & 0 \\
\hline Perennial grasslands & -19.4 & -12.61 & 59.41 & 16.48 & 23.66 \\
\hline Gorse & 21.12 & 132 & 58.75 & 0 & 41.25 \\
\hline \multicolumn{6}{|l|}{ Supratemperate vegetation } \\
\hline Mature woodland & 745.76 & 171 & 86.92 & 12.74 & 0 \\
\hline Immature woodland & -223.36 & -59.46 & 5.79 & 16.62 & 77.58 \\
\hline Broom and hawthorn & 310.8 & 105.74 & 24.99 & 22.56 & 52.45 \\
\hline Broom with perennial grasslands & -176.6 & -51.76 & 7.63 & 35.26 & 57.06 \\
\hline Perennial grasslands & -810 & -37.05 & 48.68 & 23.29 & 27.32 \\
\hline Heaths and gorse & 137.16 & 22.96 & 28.73 & 18.50 & 52.76 \\
\hline Eroded rock & -3.76 & -70.15 & 0 & 33.58 & 66.42 \\
\hline Urban areas & 14.84 & 137.92 & 100 & 0 & 0 \\
\hline Cultivated woodland & 200.8 & - & - & - & - \\
\hline Cultivated herbaceous plants & -243.8 & -99.82 & 0 & 0 & 99.93 \\
\hline \multicolumn{6}{|l|}{ Valley-floor vegetation } \\
\hline Riverside woodland & 45.96 & 303.17 & 50.66 & 49.34 & 0 \\
\hline Fields and meadows of pasture & -4.68 & -3.09 & 31.00 & 29.36 & 39.63 \\
\hline Bodies of water & -1.24 & -57.41 & 0 & 0 & 0 \\
\hline
\end{tabular}




\section{Discussion}

The indices proposed here, based on working units known as vegetation types, which entail enhanced knowledge of the vegetation, provide more precise and comprehensive information than that offered by other vegetation indices based on Landsat images. The latter have proved themselves to be useful in terms of recording the changes in plant coverage, but they do so in absolute terms of losses and gains, without taking into account the naturalness of such change [24]. One advantage of the proposed indices is that they can be applied to any territory. They may even be applied to arid regions, where the study of the vegetation by means of reflectance techniques may incur difficulties owing to the minimal wooded area occupied by the vegetation in these ecosystems, preventing substantial changes in the plant coverage from being detected [31]. The solutions to this problem currently involve the use of unmanned aerial vehicles (UAVs), as well as the establishment of vegetation types that require exhaustive knowledge of the plant communities [32].

The integration of distinct possible plant communities into a single dynamic-structural unit simplifies and facilitates the process of characterizing the landscape. In the present case study, it was especially useful with the stills from 1957, in which the task of identification at the community level would not be easy despite the availability of the current cartography. The poor image definition and the major changes in use that had taken place in a single location would render the characterization of the markings visible in earlier stills virtually impossible at the level of plant association. The vegetation types created should enable their identification and delimitation in the monochrome aerial photographs while also attaining the goals proposed: determining the structure and composition of the landscape, quantifying the findings recorded for each type of vegetation, and modelling any changes occurring over the time period in question. The resulting vegetation typology is therefore one of the most important results presented in this research. The result is not shown as a simple checklist listing vegetation types in a series of classes. This result enables the communities to be grouped in evaluable and comparable sets according to their naturalness, which helps the nature of the change to be understood based on very complete information. In addition, the results are reflected in a map that enables the most vulnerable areas, as well as those that have undergone negative changes, to be identified relatively quickly.

The results obtained from the temporal indices calculated for the case study suggest a change in the plant landscape of the territory in the direction of a higher maturity status, as is evident in Figure 4. The basis of this change is explained and accounted for by analyzing and interpreting the vegetation cartography. The most significant changes detected between 1957 and 2008, and which are likely to be relevant to the result obtained in the indices, were as follows:

1. A significant expansion of bushy formations at the expense of a reduction in the perennial grasslands, owing to successional processes (transition towards scrubland).

An expansion process involving bushy formations was observed, closer in the plant succession process to climax communities, in detriment to the area occupied by grasslands. Thus, the tracts of broom notably increased their area of occupation between 1957 and 2008. Heaths suffered a reduction, which is explained by the replacement of part of the land occupied by this type of vegetation in 1957 by forest plantations. The grasslands were reduced almost by half owing to an intense successional process, as well as replacement by cultivated forestry species. Sporadically, based on the evolution of the grassland, a type of vegetation not evident in 1957 emerged: the orophilous community of Orocantabrian oak Quercus orocantabrica Rivas Mart. et al. Despite being a species that hybridizes and forms part of woodland communities, the formations at these levels exhibit a dense bushy structure, similar to those of the scrublands of Genista obtusiramea Spach and Citysus oromediterraneus (G. López and C.E. Jarvis) Rivas Mart. et al., and their successional significance is similar. 
2. Intense process of forestation in the supratemperate vegetation and the depths of the valley.

This change proceeded from earlier successional phases (perennial grasslands and scrublands) that transitioned into mature woodlands during the temporal period in question. Moreover, the socioeconomic changes causing the abandonment of crops and pasture meadows, which are no longer exploited by humans, determined the transition of these regions towards woodland communities. The extent of woodland formations increased almost twofold. In addition to increasing quantitatively, they have also increased qualitatively: whereas in 1957 they accounted for $53.72 \%$ of climatophilous phanerophytic formations, in 2008 they reached $88.58 \%$.

3. Significant reduction in herbaceous crops, which were transformed into pasture meadows $(31 \%)$, grasslands (22\%), hawthorn (27.46\%), and woodlands (17.45\%).

These changes were fundamentally due to a demographic decline that involved a reduction in agricultural activity. The disappearance of dryland crops, shepherd-led livestock, certain management practices (e.g., irrigation of pasture, burning of gorse), and the replacement of small livestock (sheep and goats) with large animals (horses and cows) were the most important changes in the factors influencing the landscape. In general terms, the phenomenon of plants recolonizing a territory as a consequence of crop farming and other traditional practices being abandoned is one that has been observed in various parts of Europe [19,33,34].

The changes in the woodland vegetation are the ones that contributed most to the change detected by the proposed temporal indices. They involved a significant increase in the surface area occupied by climax communities in the territory (intense forestation) as well as a significant increase in the surface area covered by bushy stages close to climax, brooms being a case in point (transition to scrubland). In general terms these changes reflect a recovery in the vegetation, but also a homogenization of the landscape. This phenomenon has also been reported in areas of the Pyrenees, where the homogenization has been linked to the expansion of mature woodlands and with processes prior to heterogenization [19]. These authors link both phenomena to the elimination of preceding crops, which paves the way to the colonization of pioneering species and communities related to the natural succession and, subsequently, to the stability of the mature woodland. If the trends that have been detected persist, in 100 years the landscape will be less diverse, albeit more mature from the perspective of the serial dynamic. The homogenization of the vegetation cover related to the change in the uses of the territory is a phenomenon that has been shown in the Cantabrian mountain range at different scales and that has been related to the loss of ecosystem services [35]. This apparent contradiction between intervention and non-intervention in the natural world, management and conservation, diversity, and maturity, is a subject open to debate and of great importance to ecologists, botanists, politicians, and society at large [36,37]. Therefore, although a progression of vegetation towards climax stage is desirable, maintaining a degree of heterogeneity in the landscape mountain systems would be beneficial for the maintenance of certain ecosystem services [37]. The structure of the current landscape in the area in question, which is balanced and diverse, stems from a varied scenario dominated by pasturelands and tends, over the short term, towards a more homogeneous scenario dominated by woodlands.

An increase in the recorded surface area of vegetation in a territory is a phenomenon that has already been observed in other regions, such as China [20] and southwestern South America [38]. The fact that in some territories deforestation has stalled or even that regeneration of natural vegetation has taken place has, to a large extent, been driven by conservationist environmental policies, as has been postulated in China [20] and Argentina [38]. Although rapid economic growth and unchecked population growth lead to the degradation of vegetation and the environment-as has occurred in various parts of Mexico [18] and eastern Paraguay [38]—human activities are negatively correlated with elevation and with slope [39]. In addition, the degree of naturalness of the vegetation and the altitude have been positively related [2]. These phenomena account for the fact that such activities are concentrated in less-mountainous areas, triggering migration away from those rural areas with relatively harsh topography, as in the case of the area studied here. 
The use of temporal indices enables trends of change to be detected objectively and globally for a certain territory, enabling subsequent detailed analysis to be carried out into which plant communities are shrinking or increasing, what losses of biodiversity these transformations entail, and how the use of the territory by humans is intrinsically linked to all these processes.

\section{Conclusions}

The temporal indices of landscape change being proposed enable the changes that befall the vegetation in a territory to be detected and quantified in an objective way.

These indices need to be applied on a cartographic basis established in accordance with the methodology of modern dynamic-serial phytosociology.

They constitute an efficacious and objective tool for detecting the trend of change in a landscape, the velocity at which it is taking place and the percentage of change that will occur over specified units of time.

The indices can be applied in all territories as long as the vegetation (its composition, structure and functioning) is known at a level of detail such as that provided by the phytosociological method.

Furthermore, the precision of the information provided by these indices means that, apart from its intrinsic value, it is of great utility for supplementing other indices that analyze changes in plant coverage, such as those based on the reflectance of the territory.

In terms of the data obtained when the temporal indices were applied to a sample territory, the ConsVI score (0.057) showed a positive variation, suggesting a predominance within the territory of the progressive direction of succession, which the authors interpret on the basis of their analysis of the vegetation as an increase in bushy plants and the nanophanerophytic scrublands close to climax. The velocity of change shown by the ConSVVe score (0.011) reflected slow but positive change, in other words slow recovery of the vegetation towards more mature and stable stages in the plant succession. Lastly, the rate of change indicated by ChanRat was 1.981 (almost $2 \%$ ) over 10 years, which provides stronger evidence for this slow but continuous progress towards climax stages of vegetation at the landscape scale.

Supplementary Materials: The supplementary materials are available online at http://www.mdpi.com/2071-1050/ 11/21/5887/s1.

Author Contributions: Conceptualization, A.L.C., E.A., R.A.-R., and M.E.G.-G.; Formal analysis, A.L.C. and E.A.; Investigation, A.L.C., E.A., R.A.-R., and M.E.G.-G.; Methodology, A.L.C., E.A., R.A.-R., and M.E.G.-G.; Resources, A.L.C.; Supervision, R.A.-R. and M.E.G.-G.; Validation, A.L.C.; Visualization, R.A.-R. and M.E.G.-G.; Writing—original draft, A.L.C., E.A., R.A.-R., and M.E.G.-G.; Writing—review and editing, R.A.-R. and M.E.G.-G.

Funding: This research received no external funding.

Acknowledgments: We wish to thank Hartley Moorhouse for the text translation and his suggestions.

Conflicts of Interest: The authors declare no conflict of interest.

\section{References}

1. De Cáceres, M.; Chytrý, M.; Agrillo, E.; Attorre, F.; Botta-Dukát, Z.; Capelo, J.; Czúcz, B.; Dengler, J.; Ewald, J.; Faber-Langendoen, D.; et al. A comparative framework for broad-scale plot-based vegetation classification. Appl. Veg. Sci. 2015, 18, 543-560. [CrossRef]

2. Rüdisser, J.; Tasser, E.; Tappeiner, U. Distance to nature-A new biodiversity relevant environmental indicator set at the landscape level. Ecol. Indic. 2012, 15, 208-216. [CrossRef]

3. Pizzolotto, R.; Brandmayr, P. An index to evaluate landscape conservation state based on land-use pattern analysis and Geographic Information System techniques. Coenoses 1996, 11, 37-44.

4. Penas, A.; Del Río, S.; Herrero, L. A new methodology for the quantitative evaluation of the conservation status of vegetation: The potentiality distance index (PDI). Fitosociologia 2005, 42, 23-31.

5. Ferrari, C.; Pezzi, G.; Diani, L.; Corazza, M. Evaluating landscape quality with vegetation naturalness maps: An index and some inferences. Appl. Veg. Sci. 2008, 11, 243-250. [CrossRef] 
6. Biurrun, I.; Bergmeier, E.; Dengler, J.; Jansen, F.; Willner, W. Vegetation classification and its application are relevant globally. Phytocoenologia 2019, 49, 1-6. [CrossRef]

7. Dengler, J. Phytosociology. In The International Encyclopedia of Geography: People, the Earth, Environment and Technology; Richardson, D., Castree, N., Goodchild, M.F., Kobayshi, A.L., Liu, W., Marston, R., Eds.; Wiley-Blackwell: Chichester, UK, 2017; pp. 1-6. [CrossRef]

8. Rivas-Martínez, S. Sinfitosociología, una nueva metodología para el estudio del paisaje vegetal. An. Inst. Bot. Cavanilles 1976, 33, 179-188.

9. Raposo, M.; Conceição-Castro, M.; Gomes, C.P. The application of symphytosociology in landscape architecture. Botanique 2016, 1, 103-112.

10. Rivas-Martínez, S.; Loidi, J. Bioclimatology of the Iberian Peninsula. Itinera Geobot. 1999, 13, 41-48.

11. Rivas-Martínez, S.; Díaz, T.E.; Fernández-González, F.; Izco, J.; Loidi, J.; Lousã, M.; Penas, A. Vascular plant communities of Spain and Portugal. Addenda to the syntaxonomical checklist of 2001. Itinera Geobot. 2002, 15, 433-922.

12. Rivas-Martínez, S.; Penas, A.; Díaz, T.E.; Fernández, F. Mapa de series, geoseries y geopermaseries de vegetación de España. Memoria del mapa de vegetación potencial de España, parte I. Itinera Geobot. 2007, 17, 5-436.

13. Farina, A. Ecología del Paisaje; Publisher University of Alicante: Alicante, Spain, 2011; pp. 1-668.

14. Cantoral, A. Assesment of the Influence of the Traditional Management as A Key Element in the Maintenance of Biodiversity and Impact of Its Abandonment in the Conservation of the Mountainous Territory between the Rivers Esla and Porma. Ph.D. Thesis, University of León, León, Spain, 2015.

15. Bannari, A.; Morin, D.; Bonn, F.; Huete, A.R. A review of vegetation indices. Remote Sens. Rev. 1995, 13, 95-120. [CrossRef]

16. Sevilla, J.; Rodríguez, C. La dinámica reciente del paisaje del puerto de Leitariegos (montaña occidental asturleonesa) a través de la fotografía aérea. Ería 2015, 98, 241-274. [CrossRef]

17. Lambin, E.F.; Ehrlich, D. The surface temperature-vegetation index space for land cover and land-cover change analysis. Int. J. Remote Sens. 1996, 17, 463-487. [CrossRef]

18. Lyon, J.G.; Yuan, D.; Lunetta, R.S.; Elvidge, C.D. A change detection experiment using vegetation indices. Photogramm. Eng. Remote Sens. 1998, 64, 143-150.

19. Vicente-Serrano, S.M.; Beguería, S.; Lasanta, T. Diversidad espacial de la actividad vegetal en campos abandonados del Pirineo Central español: Análisis de los procesos de sucesión mediante imágenes Landsat (1984-2001). Pirineos 2006, 161, 59-84. [CrossRef]

20. Hu, M.; Xia, B. A significant increase in the normalized difference vegetation index during the rapid economic development in the Pearl River Delta of China. Land Degrad. Dev. 2019, 30, 359-370. [CrossRef]

21. Rouse, J.W., Jr.; Haas, R.H.; Schell, J.A.; Deering, D.W. Monitoring vegetation systems in the Great Plains with ERTS. In Third Earth Resources Technology Satellite-1 Symposium. Technical Presentations, Section B; NASA-SP-351-VOL-1-SECT-B, A 20; Freden, S.C., Mercanti, E.P., Becker, M.A., Eds.; NASA: Washington, DC, USA, 1974; Volume 1, pp. 309-317.

22. Liu, H.Q.; Huete, A. A feedback based modification of the NDVI to minimize canopy background and atmospheric noise. IEEE Trans. Geosci. Remote Sens. 1995, 33, 457-465. [CrossRef]

23. Dong, T.; Liu, J.; Shang, J.; Qian, B.; Ma, B.; Kovacs, J.M.; Walters, D.; Jiao, X.; Geng, X.; Shi, Y. Assessment of red-edge vegetation indices for crop leaf area index estimation. Remote Sens. Environ. 2019, 222, 133-143. [CrossRef]

24. Rokni, K.; Musa, T.A. Normalized difference vegetation change index: A technique for detecting vegetation changes using Landsat imagery. Catena 2019, 178, 59-63. [CrossRef]

25. Meng, Y.; Liu, X.; Wu, L.; Liu, M.; Zhang, B.; Zhao, S. Spatio-temporal variation indicators for landscape structure dynamics monitoring using dense normalized difference vegetation index time series. Ecol. Indic. 2019, 107, 105607. [CrossRef]

26. Broich, M.; Hansen, M.C.; Potapov, P.; Adusei, B.; Lindquist, E.; Stehman, S.V. Time-series analysis of multi-resolution optical imagery for quantifying forest cover loss in Sumatra and Kalimantan, Indonesia. Int. J. Appl. Earth Obs. 2011, 13, 277-291. [CrossRef]

27. Whittaker, R.H. Climax concepts and recognition. In Vegetation Dynamics; Springer: Dordrecht, The Netherlands, 1974; pp. 137-154.

28. ESRI. ArcMap 10; Environmental Systems Research Institute: Redlands, CA, USA, 2010; Available online: https://www.esri.es/arcgis/ (accessed on 6 March 2014). 
29. Díaz González, T.E.; Prieto, J.F.; García, M.Á.; Pérez, A.F.; Rodríguez, A.G. Tratamiento de los Datos del Inventario de Hábitats Derivado de la DIRECTIVA 92/43/CEE; Consejería de Agricultura. Principado de Asturias: Oviedo, España, 1996.

30. ITACYL. Fotogramas del Vuelo Americano de 1956-57 Correspondientes a la Cuenca del Duero. Available online: http://ftp.itacyl.es/cartografia/03_FotogramasAereos/Vuelo-Americano_1956-57/ (accessed on 1 December 2012).

31. Musick, H.B. Assessment of Landsat multispectral scanner spectral indexes for monitoring arid rangeland. IEEE Trans. Geosci. Remote Sens. 1984, 6, 512-519. [CrossRef]

32. Zhang, S.; Chen, H.; Fu, Y.; Niu, H.; Yang, Y.; Zhang, B. Fractional Vegetation Cover Estimation of Different Vegetation Types in the Qaidam Basin. Sustainability 2019, 11, 864. [CrossRef]

33. Torta, G. Consequences of rural abandonment in a Northern Apennines Landscape (Tuscany, Italy). In Recent Dynamics of the Mediterranean Vegetation and Landscape; Mazzoleni, S., Di Pasquale, G., Mulligan, M., Martinio, P., Di Rego, F., Eds.; Wiley and Sons Ltd: Chichester, UK, 2004; pp. 157-167.

34. Lasanta-Martínez, T.; Vicente-Serrano, S.M.; Cuadrat-Prats, J.M. Mountain Mediterranean landscape evolution caused by the abandonment of traditional primary activities: A study of the Spanish Central Pyrenees. Appl. Geogr. 2005, 25, 47-65. [CrossRef]

35. García-Llamas, P.; Geijzendorffer, I.R.; García-Nieto, A.P.; Calvo, L.; Suárez-Seoane, S.; Cramer, W. Impact of land cover change on ecosystem service supply in mountain systems: A case study in the Cantabrian Mountains (NW of Spain). Reg. Environ. Chang. 2019, 19, 529-542. [CrossRef]

36. Plieninger, T.; Kizos, T.; Bieling, C.; Dû-Blayo, L.; Budniok, M.; Bürgi, M.; Crumley, C.; Girod, G.; Howard, P.; Kolen, J. Exploring ecosystem-change and society through a landscape lens: Recent progress in European landscape research. Ecol. Soc. 2015, 20, 5-10. [CrossRef]

37. Lavorel, S.; Grigulis, K.; Leitinger, G.; Kohler, M.; Schirpke, U.; Tappeiner, U. Historical trajectories in land use pattern and grassland ecosystem services in two European alpine landscapes. Reg. Environ. Chang. 2017, 17, 2251-2264. [CrossRef]

38. Paruelo, J.M.; Garbulsky, M.F.; Guerschman, J.P.; Jobbágy, E.G. Two decades of Normalized Difference Vegetation Index changes in South America: Identifying the imprint of global change. Int. J. Remote Sens. 2004, 25, 2793-2806. [CrossRef]

39. Li, J.; Peng, S.; Zhi, L. Detecting and attributing vegetation changes on China's Loess Plateau. Agric. For. Meteorol. 2017, 247, 260-270. [CrossRef] 